\title{
Effect of Zinc-Carnosine Complex on Muscular Function in Frail Distrophin-Deficient (Mdx) Mice
}

\author{
Tsukasa TAMEYASU, Megumi OHTA, Midori TANAKA, Kyoko OGIHARA, \\ Saeko TAKAHASHI*, and Tomoyo YAMANOBE ${ }^{\dagger}$ \\ Department of Physiology, St. Marianna University School of Medicine, Kawasaki, 216-8511 Japan; \\ * Hamari Chemicals Ltd., Osaka, 533-0024 Japan; and \\ ${ }^{\dagger}$ Central Laboratory, School of Medicine, Teikyo University, Tokyo, 173-0003 Japan
}

\begin{abstract}
The effect of zinc-carnosine complex (Z-103) on muscle function in dystrophin-deficient $(\mathrm{mdx})$ mice was examined using several different courses of repetitive administration. Z103 at a dose of $100 \mathrm{mg} / \mathrm{kg}$ increased the load resistant time (LRT), during which an animal bearing a load holds himself upright on a wire net, in mdx mice when administered at an age of less than about 4 months. The effect of Z-103 on LRT was independent of sex when given by intraperitoneal (I.P.) administration between 4 and 8 weeks of age. Administration of Z-103 from the
\end{abstract}

age of 4 to 9 weeks had no significant effect on wet weight, magnitude or rate of rise of twitch force, or rate of decay of twitch force over time with twitch elicited by $0.5 \mathrm{~Hz}$ of electricity in the extensor digitorum longus muscle or calcium content in the gastrocnemius muscle, while it increased the magnitude of twitch force in the soleus muscle. These results suggest that Z-103 reduces fatigability of the whole body in $\mathrm{mdx}$ mice, possibly by increasing the contractility of slow fibers. [Japanese Journal of Physiology, 52, 449-456, 2002]

Key words: carnosine, EDL muscle, fatigue, muscular dystrophy, zinc.

$\mathrm{D}$ chenne muscular dystrophy (DMD) is a lethal genetic disease. Patients with DMD suffer progressive wasting of skeletal and cardiac muscles. They lack dystrophin, which is normally localized at the inner side of the sarcolemma of muscle and connects the intracellular cytoskeletal network of F-actin with laminin molecules in the extracellular matrix via dystroglycan complexes $[1,2]$. There is some evidence suggesting that dystrophin protects the plasma membrane in muscles from mechanical damage when the muscles contract $[3,4]$ and further that it anchors the neural nitric oxide synthase $[5,6]$, though the exact role of dystrophin is still unclear. Dystrophin-deficient (mdx) muscle exhibits a high calcium ( $\mathrm{Ca}$ ) content [7-9], though it is not certain whether this is a cause or a result of the degeneration of mdx muscle.

Pharmaceutical therapies have been tested on patients with DMD, and various therapeutic aspects have been examined in animal models. Among the drugs tested, glucocorticoids such as prednisone and de- flazacort appear to be efficacious for the treatment of mdx muscle [10-12]. Many antioxidants show no beneficial effects on mdx muscle despite the susceptibility of mdx muscle to oxidative stress [13-15]. Recently, we showed that, in male mdx mice, a zinc-carnosine complex (Z-103) that exhibits antioxidative activity and is currently being used clinically as an anti-ulcer agent $[16,17]$ reduces fatigability of the whole animal concomitantly by reducing hypertrophy, degeneration, and fatigability of fast muscle [18]. Since, however, the clinical phenotype of the mdx mouse is much milder than that of human patients, it is important to test Z-103 using animals with a severe clinical phenotype. Though it is known that some mutant dogs (e.g., golden retriever muscular dystrophy) show a quite similar phenotype to human DMD, those animals are unavailable because of their sterility [2].

During the course of studying mdx mice, we noticed that the mice became progressively more fragile as inbreeding proceeded. In the present study, we used 
such frail mdx mice after inbreeding for several years as a model with a more severe phenotype than those used in the previous study to examine the effect of Z103 on the function of $\mathrm{mdx}$ muscle. Our findings showed that Z-103 increased resistance to fatigue in the whole animal, independent of the animal's sex, after intraperitoneal (I.P.) administration, and that Z103 at the dose used in this study did not influence the contractile properties of the extensor digitus longus (EDL) muscle but increased twitch force in the soleus muscle. Ca content in $\mathrm{mdx}$ muscles was not affected by Z-103 administration.

\section{MATERIALS AND METHODS}

Preparation. C57BL/10 $\mathrm{mdx}$ and C57BL/10 $\mathrm{ScSn}$ normal mice were obtained from the Central Institute for Experimental Animals (Kawasaki, Japan). Mice were housed in cages in a room kept at a constant temperature $\left(22^{\circ} \mathrm{C}\right)$ and under a natural daynight light cycle in the Animal Laboratory at St. Marianna University. All animals were given commercial cube diet and water ad libitum. Mdx mice were inbred for several years, during which their offspring gradually became fragile. Since repeated inbreeding results in reduced fertility and a high rate of infantile mortality, the number of animals available for experiments was limited. Animals were treated in accordance with the Guiding Principles for the Care and Use of Animals approved by the Council of the Physiological Society of Japan.

Administration of Z-103. Z-103, (i.e., catena(S)-[ $\mu$ - $\left[\mathrm{N}^{\alpha}-\left(3\right.\right.$-aminopropinyl)histidinnato- $(2-) \mathrm{N}^{1}$, $\left.\mathrm{N}^{2}, \mathrm{O}: \mathrm{N}^{\tau}\right]$-zinc]) was suspended in Ringer solution (in mM: $\mathrm{NaCl} 137, \mathrm{KCl} 5, \mathrm{CaCl}_{2} 2, \mathrm{MgCl}_{2} 1, \mathrm{NaH}_{2} \mathrm{PO}_{4} 1$, $\mathrm{NaHCO}_{3} 25$, glucose 10, $\mathrm{pH} 7.4$ ), since it is insoluble in water at neutral $\mathrm{pH}(1<0.01 \%$ in weight $)$, as described previously [18]. The solution containing Z$103(10 \mu \mathrm{l})$ was administered to mice I.P. or hypodermically in the neck every other day for a total of three times a week. For the control group, Ringer solution was administered. The I.P. administration was begun at the age of 4 weeks and ended at 8 weeks for females and 9 weeks for males. Z-103 was supplied by Hamari Chemicals Ltd. (Osaka, Japan).

Mechanical performance of whole animals. To determine the fatigability of $\mathrm{mdx}$ mice, a load resistance test was employed [18]. The mdx mice were given a load equal to one half of their body weight attached to the tail by adhesive tape. They were put on a cylindrical wire net standing upright, and the time until they fell off (load resistance time, LRT) was measured. LRT was measured once a week on a day without drug administration.

Force measurement of muscles. The 9week-old male mdx mice were anesthetized with an I.P. injection of nembutal $(50 \mathrm{mg} / \mathrm{kg})$ and additional diethyl-ether anesthesia, and then placed in dishes. After partial skinning of the hind limb, tendons of the extensor digitorum longus (EDL) muscle were cut at the knee, while the other end of the EDL muscle was left intact. The severed tendon was attached to a force transducer (AE801, Aker, Norway). The EDL muscle was placed between a pair of platinum wires and stimulated with 5-ms electrical pulses at $0.5 \mathrm{~Hz}$, while it was perfused by oxygenated Ringer solution at $37^{\circ} \mathrm{C}$. Twitch force was recorded on an ink-writing oscillograph and stored together with its differential in a file on a microcomputer to measure the maximum rate of rise of twitch force. Force was expressed as $\mathrm{mN}$ per wet weight of muscle instead of cross sectional area since it was difficult to determine the muscle length accurately enough to obtain the cross sectional area. Force development of the soleus muscle was measured in a similar way to that used for the EDL muscle. After twitch force measurement, mdx mice were sacrificed by cervical dislocation.

Total $\mathrm{Ca}$ determination. $\mathrm{Ca}$ content in the muscle was determined with a method similar to that described by Deconinck et al. [19]. Isolated gastrocnemius muscles were rinsed for $15 \mathrm{~min}$ in a Ca-free Ringer solution containing $2 \mathrm{mM}$ EGTA to remove extracellular $\mathrm{Ca}^{2+}$ and then freeze-dried. Each muscle was dissolved in $1.0 \mathrm{ml}$ of concentrated $\mathrm{HCl}$. The $\mathrm{Ca}$ concentration was measured by atomic absorption flame photometry after adequate dilution in the presence of $0.5 \% \mathrm{LaCl}_{3}$. Results are expressed in $\mu \mathrm{mol}$ $\mathrm{Ca} / \mathrm{g}$ dry weight.

Statistics. Since body weight and LRT were evaluated weekly for mdx mice, repeated analysis of variance (ANOVA) was employed to determine whether or not there were any significant differences between experimental values from $\mathrm{mdx}$ mice in the treatment and control groups. Any significant effects found between the treatment and control groups were confirmed in each case by comparing mean values at each time point with Scheffe's $F$ test. ANOVA with Scheffe's $F$ test was also employed to determine the significance of differences of the rate of decay of the magnitude of twitch force over time in EDL muscles between the mdx mice treatment and control groups. Student's $t$-test was used to determine the significance of differences in wet weight, magnitude of twitch force and $\mathrm{Ca}$ contents in muscles. All experimental data are expressed as means \pm SEM, and statistical significance was determined at the $5 \%$ level $(p<0.05)$. 


\section{RESULTS}

\section{Effect of I.P. administration of Z-103 on LRT and body weight in frail $\mathrm{mdx}$ mice}

The LRT of the male control group began to decrease from the age of 6 weeks and fell to a value of about $10 \mathrm{~s}$ thereafter (Fig. 1A), while the female control group exhibited a longer LRT than the male group (Fig. 1B). Z-103 at a dose of $100 \mathrm{mg} / \mathrm{kg}$ administered I.P. from the age of 4 weeks increased LRT after the age of 6 weeks in both male and female mdx mice (Fig. 1A and B). Z-103 did not influence body weight in either male or female mdx mice (Fig. $1 \mathrm{C}$ and D).

\section{EDL muscle}

The effect of Z-103 on the EDL muscle was determined in male mdx mice administered Z-103 at a dose of $100 \mathrm{mg} / \mathrm{kg}$ from the age of 4 to 9 weeks. The wet weight of the EDL muscle was greater in control $\mathrm{mdx}$ than in normal mice. Administration of Z-103 did not influence the wet weight of the EDL muscle in $\mathrm{mdx}$ mice, as shown in Fig. 2A.

The magnitude of twitch force normalized to wet weight of the EDL muscle was smaller in the control mdx than in normal mice. Though the mean value of twitch force was greater in EDL muscles from $\mathrm{mdx}$ mice treated with Z-103 than in those from control mice, no significant difference was detected between the two because of the large variation in the former values (Fig. 2B).

Fatigability of the EDL muscle was determined by comparing the time course of decay of the magnitude of twitch force over time elicited at $0.5 \mathrm{Hs}$ (Fig. 3A). As shown in Fig. 3B, no significant difference was ob-
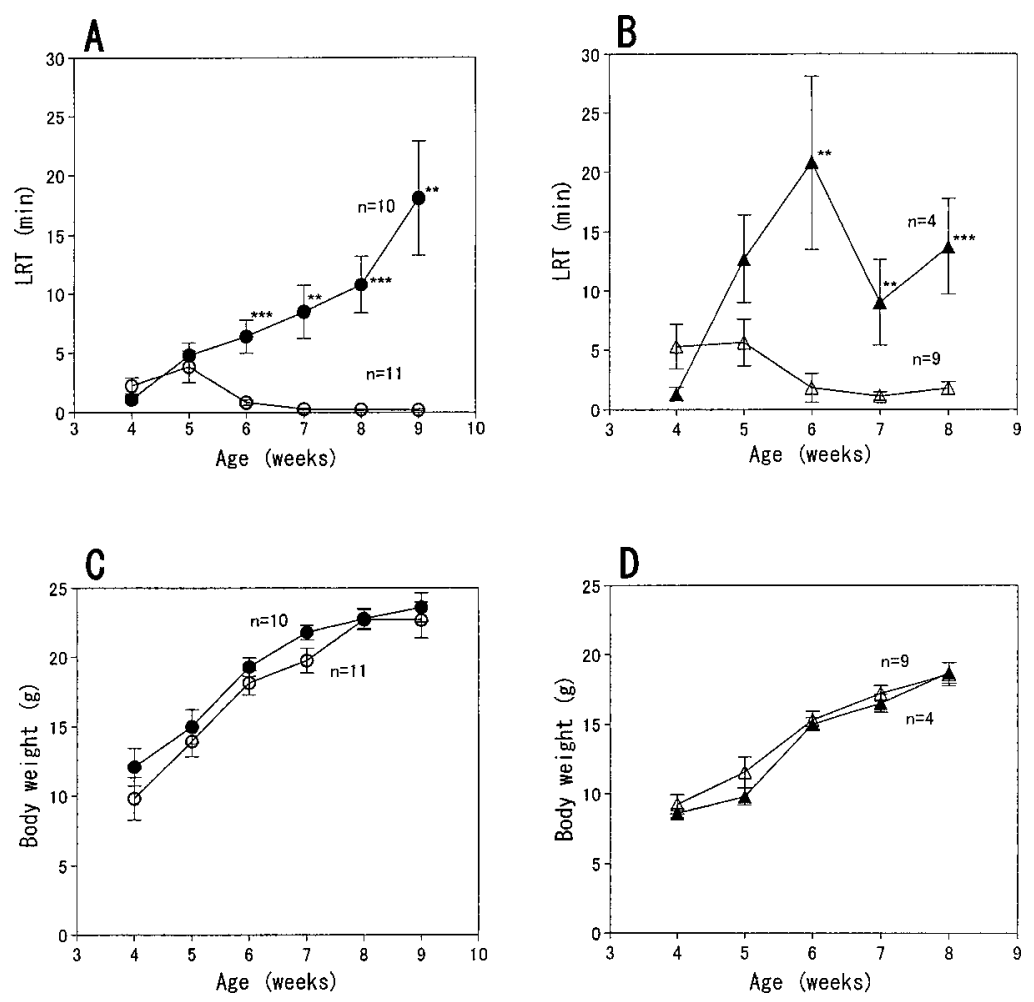

Fig. 1. Effect of I.P. administration of Z-103 on (A, B) LRT and (C, D) body weight of $\mathrm{mdx}$ mice. A and $C$, male; $B$ and $D$, female. Open symbols, control; filled symbols, mdx mice administered Z-103 at a dose of $100 \mathrm{mg} / \mathrm{kg}$ from the age of 4 to 9 weeks $(A, C)$ or 4 to 8 weeks $(B, D)$. Values presented are means $\pm S E M$; ${ }^{\star *} p<0.01,{ }^{\star * *} p<0.001$.

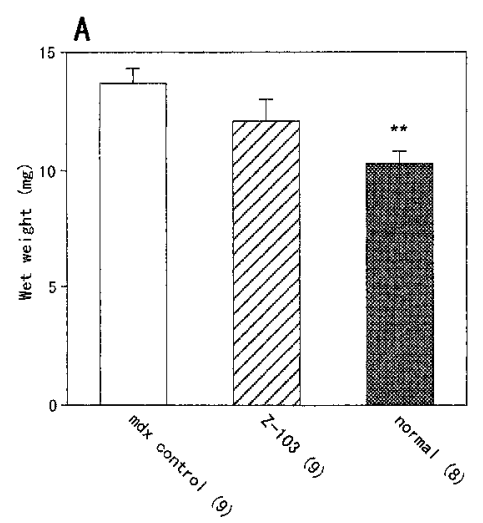

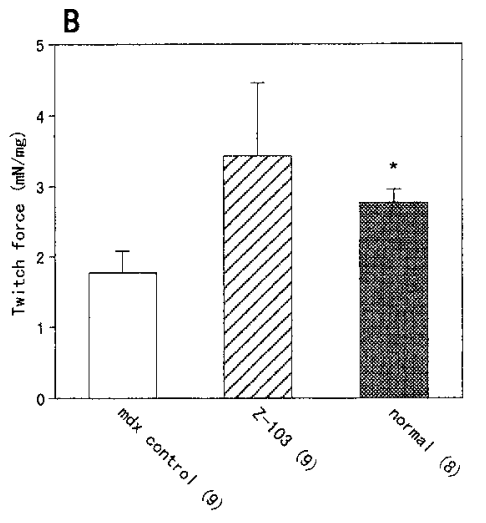

Fig. 2. Effect of Z-103 on (A) wet weight and $(B)$ twitch force in EDL muscles of 9week-old male mdx mice. Z-103 was administered at a dose of $100 \mathrm{mg} / \mathrm{kg}$ from the age of 4 to 9 weeks. Maximum twitch force was normalized by weight for individual EDL muscles. The number of samples is shown in parentheses. Data from 9-week-old normal male mice are also shown at right (indicated as normal). Statistical comparison was made against the control $\mathrm{mdx}$ mice. ${ }^{\star} p<0.05,{ }^{\star \star} p<0.01$. 
A

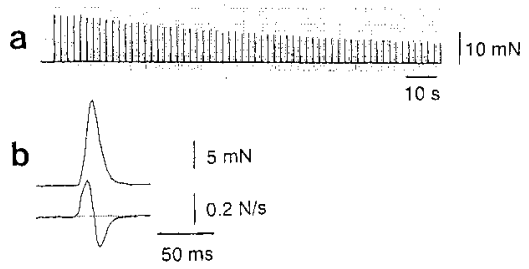

B

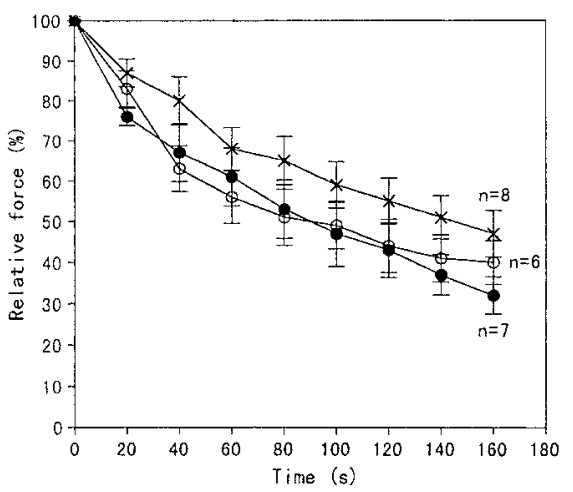

Fig. 3. Rate of decay of twitch force produced at $0.5 \mathrm{~Hz}$ by electrical stimulation of the EDL muscle. The same EDL muscle groups as in Fig. 2B were examined. A: (a) Example of twitches and (b) twitch force (upper) on a fast time base with its differential (lower). B: Rate of decay of twitch force over time. Twitch forces expressed relative to the initial maximum twitch force are shown at every $20 \mathrm{~s}$. $\mathrm{O}$, control mdx mice; $\bullet$, mdx mice administered Z-103 $(100 \mathrm{mg} / \mathrm{kg}) ; \times$, normal mice. No significant difference was found among the three.
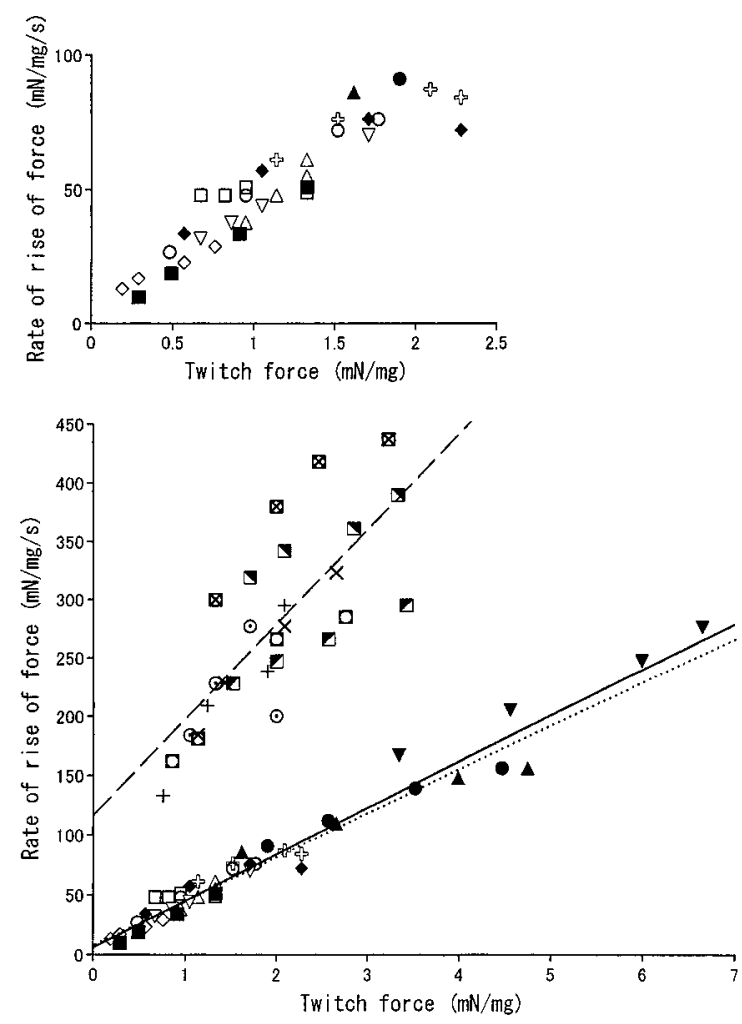

served in the rate of decay of the magnitude of twitch force over time in EDL muscles from $\mathrm{mdx}$ mice treated with Z-103 and the control group.

Contractile properties of muscle can be characterized by rate of rise as well as the magnitude of twitch force. Since the rate of rise is a function of the magnitude of the twitch force, and since the magnitude decays in successive twitches, four twitches with varying peak amplitudes were selected from individual EDL muscles for plotting the maximum rate of rise against the peak amplitude of twitch force. As shown in Fig. 4, the rate of rise of the twitch force was much greater in EDL muscles from normal mice than in that from control $\mathrm{mdx}$ mice $(p<0.001)$. The rate of rise of the twitch force was quite similar in EDL muscles from $\mathrm{mdx}$ mice administered Z-103 and those from control mdx mice (Fig. 4), indicating that Z-103 had no effect on the rate of rise of twitch contraction in the EDL muscle of the mdx mouse under the present experimental conditions.

\section{Soleus muscle}

Since the number of mdx mice available was limited, soleus muscles were obtained from both male and female $\mathrm{mdx}$ mice to determine the effect of Z-103 on them. The proportion of data obtained from females among the total mice was $3 / 5$ in control $\mathrm{mdx}$, $4 / 8$ in mdx mice administered Z-103, and $2 / 7$ in normal mice. There was no difference in wet weight of the soleus muscle between control $\mathrm{mdx}$ and normal
Fig. 4. Rate of rise of twitch force in the EDL muscle. The same EDL muscle groups as shown in Fig. 2B were examined. Maximum rate of rise vs. peak amplitude of twitch force is plotted. Upper, enlargement of the region near the origin of the lower graph; Lower, regression lines obtained by the method of least squares are $y=38.9 x+6.0\left(r^{2}=0.953\right)$ for $\mathrm{mdx}$ mice administered Z-103 at a dose of $100 \mathrm{mg} / \mathrm{kg}$ (Z$1-5$, continuous line, $y=36.8 x+9.4\left(r^{2}=0.898\right)$ for control mdx mice (m-1-6, dotted line), and $y=$ $81.2 x+114.7\left(r^{2}=0.596\right)$ for normal mice $(N-1-7$, broken line).

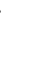



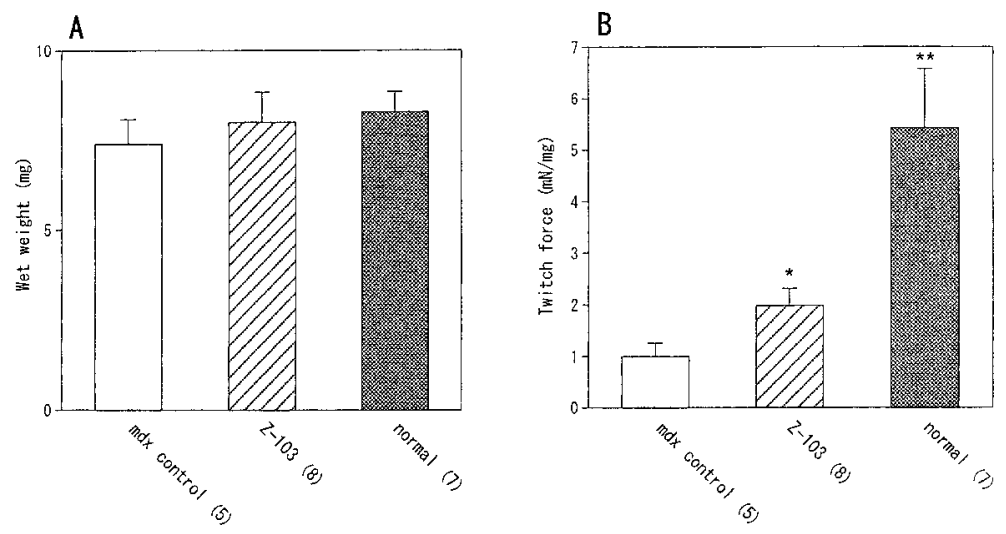

Fig. 5. Effect of Z-103 on (A) wet weight and (B) twitch force in soleus muscles from $\mathrm{mdx}$ mice. Each group contains data from male and female mice. The proportion of female to total mice was $3 / 5$ in control $\mathrm{mdx}$ mice, $4 / 8$ in $\mathrm{mdx}$ mice administered Z-103, and $2 / 7$ in normal mice. The Z-103 was administered at a dose of $100 \mathrm{mg} / \mathrm{kg}$ from the age of 4 to 9 weeks in male and 4 to 8 weeks in female mdx mice. Maximum twitch force was normalized by weight in individual EDL muscles. The number of samples is shown in parentheses. Data from 9-week-old normal mice are also shown at right (indicated as normal). Statistical comparison was made against the control $\mathrm{mdx}$ mice; ${ }^{*} p<0.05$, ${ }^{\star *} p<0.01$.

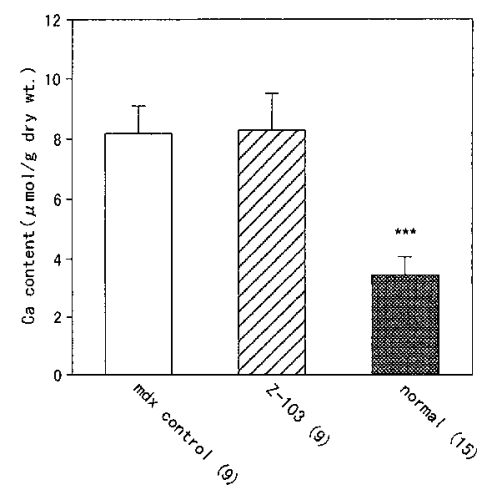

Fig. 6. Effect of Z-103 on Ca content in gastrocnemius muscle of 9-week-old male mdx mice. Z-103 (100 mg/kg) was administered from the age of 4 to 9 weeks. Statistical comparison was made against control mdx mice, ${ }^{\star * *} p<0.001$.

mice at the age of 9 weeks. As shown in Fig. 5A, I.P. administration of Z-103 at a dose of $100 \mathrm{mg} / \mathrm{kg}$ from the age of 4 to 8 weeks for female and 4 to 9 weeks for male $\mathrm{mdx}$ mice had no effect on the wet weight of their soleus muscles.

The magnitude of twitch force normalized by wet weight in the soleus muscle was smaller in control $\mathrm{mdx}$ than in normal mice $(p<0.01)$. Administration of Z-103 increased the twitch force of the soleus muscle in $\mathrm{mdx}$ mice $(p<0.05)$ (Fig. 5B). Since the soleus muscle from control mdx mice did not show any appreciable fatigue when 5 -s tetani elicited by electrical stimulation at $60 \mathrm{~Hz}$ was repeated for 7-8 min with an interval of $30 \mathrm{~s}$ at $37^{\circ} \mathrm{C}$, the effect of Z-103 on the fatigability of the soleus muscle was not examined.

\section{Ca content}

Effect of Z-103 administration on muscle Ca content was examined using the gastrocnemius muscle from 9-week-old mdx mice after 5-week-long administration of Z-103 at a dose of $100 \mathrm{mg} / \mathrm{kg}$. The results are shown in Fig. 6. The Ca content was 8.16 \pm 0.90 $\mu \mathrm{mol} / \mathrm{g}$ dry weight (mean \pm SEM, $n=9$ ) in control $\mathrm{mdx}$ mice and 3.46 $\pm 0.61 \mu \mathrm{mol} / \mathrm{g}$ dry weight $(n=15)$ in normal mice; the former was significantly greater than the latter $(p<0.001)$. This is consistent with previous reports [19]. Ca content was $8.29 \pm 1.20 \mu \mathrm{mol} / \mathrm{g}$ dry weight $(n=9)$ in $\mathrm{mdx}$ mice treated with Z-103. Thus, Z-103 had no effect on Ca content in the gastrocnemius muscle from $\mathrm{mdx}$ mice.

\section{DISCUSSION}

Contractility of EDL muscle. Z-103 at a dose of $100 \mathrm{mg} / \mathrm{kg}$ had little effect on either the wet weight or the fatigability of fast-type EDL muscle (Fig. 3) in the present study using frail mdx mice. This lack of effect of Z-103 agrees with a previous report showing that Z-103 had no effect on either the wet weight or the fatigability of the EDL muscle of 12-week-old $\mathrm{mdx}$ mice at a dose of $100 \mathrm{mg} / \mathrm{kg}$ [18].

The rate of rise of twitch force in the EDL muscle is much lower in mdx mice than normal mice (Fig. 4). This is contradictory to the report by Hayes et al. [20], in which there was no difference in the time to the peak of the twitch force between $\mathrm{mdx}$ and normal EDL muscles. The difference between their results and the present results may be due to the difference in the age of the mdx mice used: 20 and 9 weeks of age in their and our studies, respectively. Actually, we observed little difference in the rate of rise in twitch force in EDL muscles from normal and mdx mice when they were examined at the age of 12 weeks (unpublished data). Considering that degeneration followed by regeneration of EDL fibers occurs mainly between the ages of 4 and 12 weeks, together with the fact that EDL muscles fatigue much more rapidly when isolated from mdx mice at the age of 12 weeks as compared to 9 weeks (see Fig. 3 and Tameyasu et 
al. [18]), it is possible that degenerating EDL fibers develop twitch force more slowly but are more resistant to fatigue than regenerated ones in $\mathrm{mdx}$ mice.

Contractility of soleus muscle. Besides confirming that the twitch force of the soleus muscle was smaller in control mdx mice than in normal mice [21], the present results showed that Z-103 administration enhanced the twitch force without affecting the wet weight of the soleus muscle of the mdx mice (Fig. 5B). To understand the effect of Z-103 on the soleus muscle in $\mathrm{mdx}$ mice, the reason for the small twitch force in the mdx muscle should first be considered. One possible reason is the difference in composition of fast and slow fibers between mdx and normal muscles. The soleus muscle in mice is composed of a mixture of slow type I and fast type II fibers in contrast to the soleus muscle in other animal species, which is composed mainly of type I fibers [20, 22]. In the soleus muscle of the $\mathrm{C} 57 \mathrm{BL} / 10 \mathrm{ScSn}$ strain used in the present study, type I fibers constitute only about $30 \%$ of the total fibers in both normal and mdx mice at the age of 6 weeks [22]. The proportion of type I fibers rises to about $60 \%$ by the age of 26 weeks in mdx mice (i.e., it increases at rate of about $1.5 \%$ per week), while it remains constant over the next 5 months in normal mice. Therefore, in the 9-week-old mdx mice in which the contractility of the soleus muscle was examined here, the proportion of type I fibers is greater by about $5 \%$ in control $\mathrm{mdx}$ mice than in normal mice. On the other hand, the EDL muscle of the control mdx mice contained about 5\% type I fiber at 20 weeks of age, while the normal EDL muscle contained a negligible amount of type I fiber [20]. Thus, both the soleus and EDL muscles contained about 5\% more type I fiber in control mdx mice than in normal mice at 9 weeks of age. The normalized twitch force in the soleus muscle is equal to or slightly smaller than that in EDL muscles in mdx mice (Figs. $2 \mathrm{~B}$ and 5B) [20], while the former contains a much larger amount of type I fiber than the latter. Therefore, it is difficult to account for the fact that the twitch force in both the soleus and EDL muscles in $\mathrm{mdx}$ mice is about half that in normal mice by the small increase in the proportion of type I fiber in the $\mathrm{mdx}$ muscles. Another possibility is that regenerated fibers with central nuclei produce a smaller twitch force than the fibers with peripheral nuclei, which do not undergo a degeneration-regeneration process. This is possible since more than half of the total fibers are regenerated after degeneration until the age of 9 weeks in both the soleus and EDL muscles in mdx mice [23].

The percentage of centronucleated fiber in the total fibers increases markedly until the age of 4 weeks and remains unchanged thereafter in the soleus muscle in $\mathrm{mdx}$ mice, indicating that the degeneration-regeneration process of the fibers in this muscle terminates until this age. Therefore, it is difficult to ascribe the observed enhancement of twitch force in the soleus muscle through Z-103 administration (Fig. 5B) to reduction of the degeneration of fibers in the soleus muscle since Z-103 administration was begun at the age of 4 weeks. The cause of the enhancement of twitch force in the soleus muscle by Z-103 is presently uncertain.

Ca content. Contradictory results have been obtained about the $\mathrm{Ca}^{2+}$ concentration in mdx muscles. Some authors reported that the cytoplasmic $\mathrm{Ca}^{2+}$ concentration was higher in $\mathrm{mdx}$ muscle than in normal muscle, while others did not find any difference between the two. As reported with DMD patients and mdx mice [7, 8], a two-fold increase in the total $\mathrm{Ca}$ content was observed in the mdx muscle in the present study. Cytoplasmic $\mathrm{Ca}$ concentration may have little relation to the total $\mathrm{Ca}$ content [9]. Though the exact location of the excess $\mathrm{Ca}$ has not been established, it is possible that $\mathrm{Ca}$ is concentrated in $\mathrm{Ca}^{2+}$ sequestering organelles such as the sarcoplasmic reticulum and mitochondria.

Z-103 had no effect on the total $\mathrm{Ca}$ content in $\mathrm{mdx}$ muscles, as shown by examining the gastrocnemius muscle (Fig. 6). Since the gastrocnemius muscle contains both type I and II fibers, the present results suggest that Z-103 has no effect on the Ca content in either type I or II fibers in the mdx mouse.

LRT. LRT in the male mdx mice used in the present study was about $1 / 10$ th of that observed in the previous study [18], especially after the age of 6 weeks. Apparently, mdx mice become physically frail upon repetitive inbreeding for several years. The difference in the LRT between the mdx mice used in the present and the previous studies may be due to difference in expression of utorophin, a homolog of dystrophin, since utrophin appears to compensate for lack of dystrophin to some extent in mdx mice [19], and since double-mutant mice lacking both dystrophin and utorophin exhibit severe muscular dystrophy resembling human DMD [24]. Therefore, the present $\mathrm{mdx}$ mice seem to be a better model for human DMD than those used previously.

LRT in the present frail mdx mice was less than $1 / 20$ th of that of normal mice at the age of 6-7 weeks (cf. figs. 1A and 2A in Tameyasu et al. [18]). In general, physical properties such as LRT of the whole animal are affected by the contractile properties of slow muscles, the activity of motor nerves and the supply of oxygen through blood flow. Besides reduction of 
the contractility of muscle, the production of nitric oxide (NO) by neural NO synthase is disturbed in $\mathrm{mdx}$ muscle because of inappropriate localization of neural NO synthase due to the deficiency of dystrophin. This may result in insufficient dilation of blood vessels and therefore an insufficient supply of oxygen to muscles during contraction. In addition to its presence in muscle, dystrophin is also distributed in the nervous system. Therefore, decreased function of motor nerves, if it occurs, may be one of the causes of lower LRT in mdx mice.

Z-103 at a dose of $100 \mathrm{mg} / \mathrm{kg}$ had the effect of increasing LRT in frail mdx mice at several weeks of age in the present study. In accordance with the enhancement of LRT by Z-103, Z-103 had the effect of increasing force production in the soleus muscle containing more than $30 \%$ type I fiber in mdx mice (Fig. 5B). Since the constituents of $\mathrm{Z}-103\left(\mathrm{Zn}^{2+}\right.$ applied in the form of $\mathrm{ZnSO}_{4}$ and carnosine) and the combination of these two had no beneficial effect on mdx mice [18], it is thought that the effect of Z-103 on LRT is due to Z-103 itself, not its constituents. One possibility is that Z-103 spreads from the site of administration throughout the body and improves the function of leg muscles. Another possibility is that Z-103 stays at the site of administration and exerts its effect via some mediator which spreads throughout the body. In this connection, it is worth noting that, in cell cultures, Z103 has the effect of enhancing the proliferation of some kinds of cells by acting as an insulin-like growth factor [25], suggesting complex effects of Z-103 in situ.

We would like to thank Dr. I. Mitsuyoshi (Pediatrics Department, Utano Hospital) for generous advice. This work was financially supported in part by Hamari Chemicals Ltd.

\section{REFERENCES}

1. Gillis JM: Understanding dystrophinopathies: an inventory of the structural and functional consequences of the absence of dystrophin in muscles of the $\mathrm{mdx}$ mouse. J Musc Res Cell Motil 20: 605-625, 1999

2. Sabine DLP, Sophie M, and Koenig J: Characteristics of skeletal muscle in mdx mutant mice. Int Rev Cytol 191: 99-148, 1999

3. Moens P, Baatsen PHWW, and Marechal G: Increased susceptibility of EDL muscles from $\mathrm{mdx}$ mice to damage induced by contractions with stretch. J Musc Res Cell Motil 14: 446-451, 1993

4. Petrof BJ, Shrager JB, Stedman HH, Kelly AM, and Sweeney HL: Dystrophin protests the sarcolemma from stresses developed during muscle contraction. Proc Natl Acad Sci USA 90: 3710-3714, 1993

5. Brenman JE, Chao DS, Xia H, Aldape K, and Bredt DS: Nitric oxide synthase complexed with dystrophin and absent from skeletal muscle sarcolemma in Duchenne muscular dystrophy. Cell 82: 743-752, 1995

6. Chang WJ, lannaccone ST, Lau KS, Masters BS, McGabe TJ, McMillan K, Radre RC, Spencer MJ, Tidball JG, and Stull JT: Neuronic nitric oxide synthase and dystrophin-deficient muscular dystrophy. Proc Natl Acad Sci USA 93: 9142-9147, 1996

7. Bodensteiner JB and Angel AG: Intracellular calcium accumulation in Duchenne dystrophy and other myopathies: a study of 567,000 muscle fibres in 114 biopsies. Neurology 28: 439-446, 1978

8. McArdle A, Edwards RHT, and Jackson MJ: Accumulation of calcium by normal and dystrophin-deficient mouse muscle during contractile activity in vitro. Clin Sci 82: 455-459, 1992

9. Gailly P, Boland B, Himpens B, Casteels R, and Gillis JM: Critical evaluation of cytosolic calcium determination in resting muscle fibres from normal and dystrophic (mdx) mice. Cell calcium 14: 437-483, 1993

10. Metzinger L, Passaquin AC, Warter JM, and Poindron $P$ : $\alpha$-Methylprednisone promotes skeletal myogenesis in dystrophin-deficient and control mouse cultures. Neurosci Lett 155: 171-174, 1993

11. Passaquin AC, Methzinger L, Leger JJ, Warter JM, and Poindron P: Prednisone enhances myogenesis and dystrophin-related protein in skeletal muscle cell cultures from mdx mouse. J Neurosci Res 35: 363-372, 1993

12. Anderson JE, McIntosh LM, and Poettcker R: Deflazacort but not prednisone improves both repair and fiber growth in diaphragm and limb muscle in vivo in the mdx dystrophic mouse. Muscle Nerve 19: 1576-1585, 1996

13. Distnik $M H$, Dhawan J, Yu Y, Beal MF, Whirl MM, Franco AA, and Rando TA: Evidence of oxidative stress in mdx mouse muscle: studies of the pre-necrotic state. J Neurol Sci 26: 77-84, 1998

14. Jackson MJ and Edwards RHT: Therapeutic trials of antioxidants in muscle diseases. In: Oxidative Stress in Skeletal Muscle, ed. Reznik AZ, Packer L, Sen CK, Holloszy JO, and Jackson MJ, Birkhäuser Verlag, Basel, pp 327-333, 1998

15. Rando TA, Disatnik MH, Yu Y, and Franco AA: Muscle cells from $\mathrm{mdx}$ mice have an increased susceptibility to oxidative stress. Neuromuscul Disord 8: 14-21, 1998

16. Cho $\mathrm{CH}$, Luk CT, and Ogle CW: The membrane-stabilizing action of zinc carnosine (Z-103) in stress-induced gastric ulceration in rats. Life Sci 49: 189-194, 1991

17. Yoshikawa T, Naito Y, Tanigawa T, Yoneta T, and Kondo $M$ : The antioxidant properties of a novel zinc-carnosine chelate compound, N-(3-aminopropinyl)-L-histidinato zinc. Biochim Biophys Acta 1115: 15-22, 1991

18. Tameyasu T, Yamada M, Tanaka M, and Takahashi S: Effect of zinc-carnosine chelate compound on muscle function in mdx mouse. Jpn J Physiol 52: 111-120, 2002

19. Deconinck N, Tinsley J, Backer FD, Fisher R, Kahn D, Phelps S, Davies K, and Gillis JM: Expression of truncated utrophin leads to major functional improvements in dystrophin-deficient muscles of mice. Nat Med 3: 1216-1221, 1997

20. Hayes A, Lynch GS, and Williams DA: The effects of 


\section{T. TAMEYASU et al.}

endurance exercise on dystrophic $m d x$ mice. I. Contractile and histochemical properties of intact muscles. Proc R Soc Lond B 253: 19-25, 1993

21. Dupont-Versteegden EE and Mccarter RJ: Differential expression of muscular dystrophy in diaphragm versus hindlimb muscles of mdx mice. Muscle Nerve 15: 1105-1110, 1992

22. Carnwath JW and Shotton DM: Muscular dystrophy in the $m d x$ mouse: histopathology of the soleus and extensor digitorum longus muscles. J Neuro Sci 80: 39-54, 1987

23. Pastoret $\mathrm{C}$ and Sebille $\mathrm{A}$ : $M d x$ mice show progressive weakness and muscle deterioration with age. J Neurol Sci 129: 97-105, 1995

24. Deconinck AE, Rafael JA, Skinner JA, Brown SC, Potter AC, Metzinger L, Watt DJ, Dickson JG, Tinsley JM, and Davies KE: Utorophin-dystrophin-deficient mice as a model for Duchenne muscular dystrophy. Cell 90: 717-727, 1997

25. Seto K, Yoneta $\mathrm{T}$, Suda $\mathrm{H}$, and Tamaki H: Effect of polaprezinc ( $\mathrm{N}$-(3-aminopropionyl)-L-histidinato zinc), a novel antiulcer agent containing zinc, on cellular proliferation: role of insulin-like growth factor I. Biochem Pharmacol 58: 245-250, 1999 